\title{
Enhanced Resistance to Sclerotium rolfsii in Populations of Alfalfa Selected for Quantitative Resistance to Sclerotinia trifoliorum
}

\author{
R. G. Pratt and D. E. Rowe
}

U.S. Department of Agriculture, Agricultural Research Service, Waste Management and Forage Research Unit, P.O. Box 5367, Mississippi State, MS 39762.

Accepted for publication 6 November 2001.

\begin{abstract}
Pratt, R. G., and Rowe, D. E. 2002. Enhanced resistance to Sclerotium rolfsii in populations of alfalfa selected for resistance to Sclerotinia trifoliorum. Phytopathology 92:204-209.

Sclerotinia trifoliorum and Sclerotium rolfsii are pathogens for which similar mechanisms of parasitism have been proposed. This suggested that resistance to these pathogens may be related in a common host plant. This study was undertaken to determine whether selection for quantitative resistance to Sclerotinia trifoliorum in alfalfa also increases resistance to Sclerotium rolfsii as expressed in excised leaf tissues and whole plants. Resistance in excised leaf tissues was evaluated according to the rate of necrosis induced by Sclerotium rolfsii following inoculation with mycelium. Resistance to Sclerotium rolfsii in whole plants was evaluated according to their survival following crown inoculations. Three alfalfa populations previously selected from cv. Delta for quantitative resistance to Sclerotinia trifoliorum exhibited enhanced resistance to Sclerotium rolfsii, in comparison with Delta or with susceptible populations, in excised leaf tissues. When whole plants of Delta and two of these populations, Sclerotinia trifoliorum resistant (STR) and Mississippi

Sclerotinia resistant (MSR), were inoculated with Sclerotium rolfsii at 3 to 8 weeks of age, significant $(P=0.01)$ differences in survival were attributed to plant age at inoculation and alfalfa populations. Survival of both MSR and STR was significantly $(P=0.05)$ greater than for Delta; the best differential results were obtained by inoculating plants 5 to 7 weeks old. To evaluate relationships of resistance to Sclerotinia trifoliorum and Sclerotium rolfsii over a broader genetic background, additional populations were selected for resistance to Sclerotinia trifoliorum from four other alfalfa cultivars by leaf-inoculation techniques, and this resistance was confirmed by whole-plant inoculations. In excised leaf tissues, all four of these populations also expressed enhanced resistance to Sclerotium rolfsii in comparison with either parent cultivars or populations of comparable size selected at random. These results establish that selection for quantitative resistance to Sclerotinia trifoliorum in alfalfa also confers enhanced resistance to Sclerotium rolfsii as expressed in excised leaf tissues and whole plants. Results suggest, therefore, that genes for quantitative resistance to Sclerotinia trifoliorum and Sclerotium rolfsii in alfalfa are likely to be synonymous, overlapping, or closely linked.
\end{abstract}

Sclerotinia trifoliorum Eriks. and Sclerotium rolfsii Sacc. are taxonomically and ecologically diverse pathogens of alfalfa in the southeastern United States. Sclerotinia trifoliorum is an ascomycete that can damage or destroy first-year stands of fall-seeded alfalfa. Disease is initiated by ascospore infection in late autumn and involves rotting of leaves, stems, and crowns, and death of plants, during winter and early spring. Disease occurs only on alfalfa, clover, and other forage legumes among cultivated crops, but nonleguminous weeds also may be infected (24). Sclerotium rolfsii, in contrast, is the imperfect stage of a basidiomycete (Athelia rolfsii (Curzi) Tu \& Kimbrough) that causes disease only during summer months (2). Infection is initiated by direct penetration of hyphae following mycelial germination of sclerotia in soil and thatch and often is preceded by saprophytic growth. Symptoms consist primarily of water-soaked rotting of infected leaves, stems, and roots. $S$. rolfsii attacks a wide range of dicotyledonous plants and some grasses (2); it has been reported on alfalfa (Medicago sativa L.) in numerous states in the Southeast (5) and occasionally caused significant losses (1).

Despite broad taxonomic and ecological differences between them, Sclerotinia trifoliorum and Sclerotium rolfsii are believed to cause disease in plants by fundamentally similar mechanisms of parasitism. Both fungi are believed to secrete oxalic acid and pec-

Corresponding author: R. G. Pratt; E-mail address: rpratt@msa-msstate.ars.usda.gov

Publication no. P-2001-1220-01R

This article is in the public domain and not copyrightable. It may be freely reprinted with customary crediting of the source. The American Phytopathological Society, 2002. tinolytic enzymes in infected host tissue during pathogenesis $(3,6$, $7,12,13,15,23,26)$; these compounds may act independently (7) or in concert $(3,12,23)$ to sequester calcium from cell walls, hydrolyze pectin compounds, lower $\mathrm{pH}$, and suppress host defensive responses $(6,12)$.

Resistance to Sclerotinia trifoliorum in alfalfa, as elucidated in recent years $(9,16-21)$, manifests all of the characteristics of a quantitative genetic system. In such a system, differences in host phenotype comprise a continuous gradient from the most highly resistant to the most highly susceptible, with no discrete categories or separations within it (4). Such quantitative phenotypic gradients are caused primarily by additive interactions of alleles at multiple loci, and dominance-recessive relationships between genes are minimal or nonexistent $(4,8)$. Expression of resistance in quantitative systems is often variable and strongly influenced by procedural and environmental variables such as inoculum level and light intensity (14). In responses of alfalfa to infection by Sclerotinia trifoliorum, quantitative phenotypic gradients in resistance and susceptibility are manifested at all levels of genetic organization, from cultivars to families to individual progeny of selfs or crosses $(9,17,19)$. Successful breeding for resistance in this and other quantitative systems consists of moving population means toward the resistant end of the gradient $(17,25)$.

Rapid progress in selection for resistance to Sclerotinia trifoliorum in alfalfa has been made in recent years. Selection for heritable resistance has been demonstrated by stem $(9,18)$, leaf $(17)$, and whole-plant (16) inoculation techniques. Selection by stem and leaf inoculation techniques has given increased resistance in progeny that was expressed in excised leaves (17), in excised stems $(17,18)$, with whole-plant inoculations under controlled conditions 
$(17-19,21)$, and with natural infection in the field as measured both by reduced disease severity $(18,21)$ and increased yield $(17,20)$.

For Sclerotium rolfsii on alfalfa, attempts to evaluate or select for host resistance have not been reported from North America. In Japan, however, cultivar differences in severity of disease caused by Sclerotium rolfsii were observed following natural infection (11). Selection for reduced mortality or disease severity in naturally infected populations gave positive responses in progeny (10).

If mechanisms of parasitism are similar for Sclerotinia spp. and Sclerotium rolfsii, as past research has suggested $(3,6,12,13,23)$, then it appeared reasonable that resistance to the two pathogens may be related in a common host plant. The availability of multiple populations of alfalfa with resistance to Sclerotinia trifoliorum, recently developed from cv. Delta $(17,18,21)$, and knowledge of how to efficiently select for resistance from other sources (17), afforded an opportunity to test this hypothesis. Therefore, this study was undertaken to determine whether enhanced resistance to Sclerotium rolfsii is present in excised leaf tissues and whole plants of alfalfa populations selected for quantitative resistance to Sclerotinia trifoliorum.

Resistance to Sclerotium rolfsii was evaluated primarily by inoculation of excised leaf tissues because these enabled rapid assays of numerous genotypes with minimal time, space, and effort. Resistance to Sclerotium rolfsii was evaluated both in three populations previously selected for resistance to Sclerotinia trifoliorum from cv. Delta and in four additional populations newly selected from four other alfalfa cultivars. Whole plants of cv. Delta and two of the Sclerotinia-resistant populations derived from it also were inoculated with Sclerotium rolfsii, and mortality was evaluated, to verify that the enhanced resistance observed in excised leaves is also expressed in whole plants. A preliminary report has been presented (22).

\section{MATERIALS AND METHODS}

Alfalfa populations previously selected for resistance to Sclerotinia trifoliorum from cv. Delta. Three alfalfa populations previously selected for resistance to Sclerotinia trifoliorum from cv. Delta, Sclerotinia trifoliorum resistant (STR), Mississippi Sclerotinia resistant (MSR), and "resistant progeny," were evaluated for responses to Sclerotium rolfsii in comparison with Delta by inoculation of excised leaf tissues and whole plants. The resistant progeny population also was compared to susceptible and randomly selected populations from Delta. STR and MSR also were evaluated by whole-plant inoculations.

STR is an experimental population selected by stem inoculations. Resistance of STR was expressed following stem inoculations, whole-plant inoculations, and natural infection in the field (18).

MSR was selected largely by leaf inoculations (17) and released as a Sclerotinia-resistant germ plasm (21). In whole-plant inoculation experiments, MSR was more resistant to Sclerotinia trifoliorum than 26 cultivars, and resistance was expressed against multiple isolates of both Sclerotinia trifoliorum and Sclerotinia sclerotiorum. The resistance of MSR also was manifested with natural infection in the field $(20,21)$.

The resistant progeny population was produced by intercrossing plants selected for resistance entirely by leaf-inoculation techniques to demonstrate their effectiveness (17). Progeny also were produced from plants selected for susceptibility to Sclerotinia trifoliorum ("susceptible progeny") and selected at random ("random progeny") to provide additional controls. Resistant progeny exhibited resistance to Sclerotinia trifoliorum in comparison with Delta, random progeny, and susceptible progeny in excised leaf tissue, excised stems, whole plants, and with natural infection in the field (17). In the present study with Sclerotium rolfsii, resistant progeny were compared with susceptible progeny and random progeny in addition to Delta by inoculation of excised leaf tissue.

Growth of plants and preparation of inoculum. Alfalfa seed germinated for 2 to 3 days on inverted plates of water agar were planted by hand in cone-shaped plastic cylinders $(12 \mathrm{~cm}$ deep, $45-\mathrm{cm}^{3}$ capacity) containing a commercial potting mixture (Jiffy Products of America, Batavia, IL), nodulated with Rhizobium meliloti Dangead, and grown in the greenhouse with weekly fertilization as described elsewhere (18). An isolate of Sclerotium rolfsii from white clover (Trifolium repens L.) in Mississippi was maintained as air-dried sclerotia at room temperature. To generate colonies, sclerotia were hydrated with sterile water, bisected, and placed on Difco cornmeal agar (CMA) (Difco Laboratories, Detroit). Agar disks from colony margins on CMA were used to inoculate leaf disks and crowns of whole plants. The isolate of Sclerotinia trifoliorum (Alf-2) from previous studies (17-19) also was used here to select for resistance from additional alfalfa cultivars and to evaluate resistance of populations. It was maintained as air-dried sclerotia, and colonies were generated as for Sclerotium rolfsii. Mixtures of wheat and oat grain were infested with Sclerotinia trifoliorum, dried, comminuted, and applied to foliage for whole-plant inoculations as in previous studies (17-19).

Inoculation of excised leaf tissues with Sclerotium rolfsii and evaluation of symptom development. All alfalfa populations selected for resistance to Sclerotinia trifoliorum were evaluated for responses to Sclerotium rolfsii, in comparison with parental cultivars \pm other populations, in excised leaf tissues. Leaflets of trifoliolate leaves were collected and inoculated with Sclerotium rolfsii by a method similar to that used previously with Sclerotinia trifoliorum (17). Specifically, a terminal leaflet was collected from the second fully expanded leaf proximal from a growing stem tip, and a disk (12 $\mathrm{mm}$ in diameter) was cut from the leaflet and placed in a small petri dish $(3.5 \mathrm{~cm}$ in diameter) containing water agar. A disk of agar and mycelium (4 $\mathrm{mm}$ in diameter) was cut from the growing colony margin of Sclerotium rolfsii on Difco CMA and inverted over the center of each leaf disk. Plates with inoculated leaf disks were incubated under fluorescent plant growth lights (80 mols $\mathrm{m}^{-2} \mathrm{~s}^{-1}$ intensity, 12-h photoperiod) at $24^{\circ} \mathrm{C}$. Leaf disks were observed daily for 7 days and scored as described for Sclerotinia trifoliorum (17). Scores were assigned inversely according to days when tissue became completely necrotic within a week after inoculation (e.g., disks completely necrotic at 2, 3, 4, 5, 6, and 7 days after inoculation were scored " 6 ", "5", "4", "3", "2", and "1", respectively). Disks not completely necrotic at 7 days after inoculation were scored " 0.00 " to " 0.99 " based on the percentage of tissue estimated to be necrotic ( 0.00 to 0.99). Controls with noninfested agar were not utilized because necrosis did not develop in uninoculated leaf disks during incubation for a week under growth lights.

The MSR and STR populations each were compared with cv. Delta in separate, repeated experiments with 50 replicate leaves of each treatment arranged in completely random designs on the growth bench. Means of the two treatments in each experiment were compared by analysis of variance (ANOVA) $(P=0.05)$. Resistant progeny were compared with Delta and also with susceptible progeny and random progeny in the same manner and by use of Fisher's protected least significant difference (LSD) test $(P=$ $0.05)$. In populations newly selected for resistance to Sclerotinia trifoliorum from other alfalfa cultivars, resistant progeny from each cultivar were compared with the parent cultivars and also to progeny of randomly selected plants (random progeny) in separate, repeated experiments with 50 replicate leaves of each treatment arranged in completely random designs. Treatment means were compared by ANOVA and use of Fisher's protected LSD test $(P=$ $0.05)$.

Inoculation of whole plants with Sclerotium rolfsii. Wholeplant inoculations were performed with Sclerotium rolfsii and plants of Delta, MSR, and STR at six ages to verify that differ- 
ences in resistance observed in excised leaves also were expressed in whole plants. For each experimental unit, eight cones with plants of a single population were placed in a clay pot $(10.5 \mathrm{~cm}$ in diameter, 374- $\mathrm{cm}^{3}$ capacity) and sand was added around cones to hold them erect as in previous studies $(18,19)$. Size differences between plants in each population were randomized among pots. To inoculate a plant, potting mixture was scraped away to expose one side of the upper taproot, and the surface of a disk of agar and mycelium (12 $\mathrm{mm}$ in diameter) from a colony margin on CMA was appressed to the upper taproot and crown with growing hyphal tips pointed vertically toward the stem. Sand was added to cover the agar disk and base of the stem. Each pot with eight inoculated plants was placed in a plastic cup $\left(8 \mathrm{~cm}\right.$ high, $560-\mathrm{cm}^{3}$ capacity), and the cup was placed in a transparent plastic bag (42 cm high, 4.3-liter capacity) containing approximately $180 \mathrm{ml}$ of water. The bag was drawn up over stems and sealed to create a humidity chamber (19). Pots were placed on benches under the growth lights at 23 to $27^{\circ} \mathrm{C}$. After 3 days, bags were removed and plants were maintained under the same conditions in ambient air until 24 days after inoculation, when numbers of plants killed by Sclerotium rolfsii in each pot were recorded.

In each of two whole-plant inoculation experiments with Sclerotium rolfsii, plants of STR, MSR, and Delta were inoculated at $3,4,5,6,7$, and 8 weeks of age. Ten replicate pots of each treatment were arranged in a randomized complete-block design. Main effects and interactions of alfalfa populations and plant age were evaluated by ANOVA for a 3-by-6 factorial experiment. Significant differences between alfalfa populations based on mean numbers of plants killed per pot were identified by Fisher's protected LSD test $(P=0.05)$. Responses to plant age were evaluated by regression analysis using SAS procedures (SAS Institute, Cary, NC).

Selection and evaluation of additional alfalfa populations with resistance to Sclerotinia trifoliorum. Populations with resistance to Sclerotinia trifoliorum were selected from four additional alfalfa cultivars and evaluated for responses to Sclerotium rolfsii to determine whether resistance to the two pathogens is related over a broad genetic background. Cvs. Magnum-III-Wet, Pioneer 5472, WAMPR, and WL-323 were chosen as sources for

TABLE 1. Mean scores for disease severity induced by Sclerotium rolfsii in excised leaf tissues of alfalfa cv. Delta and of populations previously selected from it for resistance and susceptibility to Sclerotinia trifoliorum, and selected at random ${ }^{\mathrm{x}}$

\begin{tabular}{lcc}
\hline & \multicolumn{2}{c}{ Mean scores $^{\mathrm{z}}$} \\
\cline { 2 - 3 } Group, populations & \\
\hline 1 & Experiment 1 & Experiment $2^{\mathrm{y}}$ \\
Delta & $3.74 \mathrm{a}$ & $4.04 \mathrm{a}$ \\
MSR & $2.40 \mathrm{~b}$ & $1.83 \mathrm{~b}$ \\
2 & $3.69 \mathrm{a}$ & \\
Delta & $2.53 \mathrm{~b}$ & $4.21 \mathrm{a}$ \\
STR & & $2.23 \mathrm{~b}$ \\
3 & $2.58 \mathrm{~b}$ & \\
Delta & $3.75 \mathrm{a}$ & $4.22 \mathrm{~b}$ \\
Random progeny & $3.87 \mathrm{a}$ & $4.80 \mathrm{a}$ \\
Susceptible progeny & $2.17 \mathrm{~b}$ & $4.94 \mathrm{a}$ \\
Resistant progeny & $2.91 \mathrm{c}$ \\
\hline
\end{tabular}

${ }^{\mathrm{x}}$ Each value is the mean disease score for 50 replicate leaf disks, one disk per plant. High mean scores indicate greater severity of symptoms, low mean scores indicate lesser severity. Scores of 1 to 7 were assigned inversely according to days on which leaf disks became completely necrotic within 1 week after inoculation. For leaf disks not completely necrotic after 1 week, scores of 0.00 to 0.99 were assigned according to estimates of percentages of tissue that were necrotic.

${ }^{\text {y }}$ MSR = Mississippi Sclerotinia resistant (21); STR = Sclerotinia trifoliorum resistant (18); resistant, random, and susceptible progeny (17).

${ }^{\mathrm{z}}$ Means within experiments and population groups not followed by the same letter differ significantly at $P=0.05$ according to the least significant difference test. selection of additional populations with resistance to Sclerotinia trifoliorum because they derive from four private breeding programs and are not the most susceptible to isolates of Sclerotinia trifoliorum and Sclerotinia sclerotiorum (19). One thousand plants of each cultivar were screened for resistance by leaf-inoculation techniques as described (17), beginning at 10 to 11 days of age, in seven or eight successive experiments with unifoliolate leaves and trifoliolate leaflets. After each screening experiment, the most susceptible-appearing $50 \%$ or more of plants were eliminated. The 10 most resistant-appearing plants from each cultivar were intercrossed to produce each resistant population. Ten additional plants from each cultivar were selected at random and intercrossed to produce a random population as a control for reduced population size.

Resistant populations, random populations, and the parent cultivars were compared for survival following inoculation of 3 and 1/2- to 4-week-old plants with comminuted, infested grain inoculum of Sclerotinia trifoliorum that was applied to foliage as in previous studies (17-19). In all, 12 to 15 replicate pots (eight plants per pot) of each population were inoculated in each experiment. Two experiments were performed for each cultivar and the resistant and random populations selected from it. In each experiment, plants were arranged in a randomized complete-block design and grown under the growth lights at 15 to $19^{\circ} \mathrm{C}$ for the duration of the experiment. Survival was evaluated at 24 days after inoculation, and mean numbers of surviving plants in each treatment were compared by ANOVA and use of Fisher's protected LSD test $(P=0.05)$. When significant differences were inconsistent between experiments, ANOVA was performed on combined results if heterogeneity of variance was not significant $(P=0.05)$.

\section{RESULTS}

Resistance to Sclerotium rolfsii in excised leaf tissues of alfalfa populations from cv. Delta. Mean disease scores of the MSR and STR populations, previously selected for resistance to Sclerotinia trifoliorum from cv. Delta, were both significantly less than for Delta after inoculation with Sclerotium rolfsii in each of two experiments (Table 1). Mean scores of resistant progeny were significantly less than for Delta in one experiment and less than scores of random progeny and susceptible progeny in both experiments (Table 1). The ranking of mean scores following inoculation with Sclerotium rolfsii (resistant progeny $<$ Delta $<$ random progeny $<$ susceptible progeny) was the same as that observed previously following leaf inoculations with Sclerotinia trifoliorum (17).

Resistance to Sclerotium rolfsii in whole plants of alfalfa populations from cv. Delta. Plants of all treatments often became slightly wilted after exposure to ambient air following incubation for 3 days in sealed plastic bags, but this wilting usually disappeared after $24 \mathrm{~h}$. Initial symptoms of disease developed on some plants in the youngest age groups of Delta and the MSR and STR populations by 3 days after inoculation. Leaves and stems

TABLE 2. Sources of variation and their significance for mortality induced by Sclerotium rolfsii in two experiments with alfalfa plants of six ages from three populations

\begin{tabular}{lrc}
\hline Experiment, source of variation & df & $F$ value and significance $^{\mathrm{z}}$ \\
\hline 1 & 5 & $65.64 * *$ \\
Plant age & 2 & $9.53 * *$ \\
Alfalfa populations & 10 & $0.63 \mathrm{NS}$ \\
Age $\times$ populations & & \\
2 & 5 & $112.75 * *$ \\
Plant age & 2 & $6.68 * *$ \\
Alfalfa populations & 10 & $2.11 *$ \\
Age $\times$ populations & & \\
\hline
\end{tabular}

$\mathrm{z} *$ and $* *$ indicate $P=0.05$ and 0.01 , respectively; NS $=$ not significant at $P=0.05$. 
wilted and visible white mycelium emanated from bases of stems. Most wilted plants collapsed and died within several days. Numerous additional plants continued to wilt and die during the next 7 to 10 days, but further initiation of symptoms and mortality then occurred only sporadically. By 24 days after inoculation, nearly all surviving plants showed new stem and leaf growth with no incipient disease symptoms.

In both experiments, significant differences in mortality were attributed to plant age and alfalfa populations. In one experiment, an interaction between these factors was significant $(P=0.05)$, whereas in the other it was not (Table 2). Mortality was greatest in plants 3 or 4 weeks old at time of inoculation (means 61 and $60 \%$, respectively, across populations and experiments), and it decreased to very low levels in plants 8 weeks old (mean 3\% across populations and experiments). Regression equations for mortality at different plant ages were computed for each experiment and slopes were compared. There was no significant $(P=0.05)$ difference between slopes; therefore, data were combined over experiments and a linear regression equation was computed as: mortality $=8.29-1.06$ (plant age at time of inoculation). The slope of this equation differed significantly from zero $\left(r^{2}=0.82\right)$. Across plant ages, mortality was significantly $(P=0.05)$ greater in cv. Delta than in the MSR and STR populations in both experiments (Table 3 ).

Selection and evaluation of alfalfa populations with resistance to Sclerotinia trifoliorum from other cultivars. Populations selected for resistance to Sclerotinia trifoliorum from cvs. Magnum-III-Wet, Pioneer 5472, and WL-323 exhibited significantly greater survival of plants than both the parent cultivars and random populations following inoculation with Sclerotinia trifoliorum (Table 4). The population selected for resistance from WAMPR exhibited greater survival than both the parent cultivar and the random population in one experiment, while significant differences did not occur in the other. When results of the two experiments were combined, the population selected for resistance exhibited significantly greater survival than both the parent cultivar and random population.

Resistance to Sclerotium rolfsii in excised leaf tissues of alfalfa populations from other cultivars. Following inoculation of excised leaf tissues with Sclerotium rolfsii, mean disease scores of populations selected for resistance to Sclerotinia trifoliorum from the four alfalfa cultivars were significantly less than for the parent cultivars and random populations in all experiments (Table 5). Random populations usually did not differ significantly from parent cultivars.

\section{DISCUSSION}

Results of this study demonstrate that enhanced resistance to Sclerotium rolfsii, as manifested by a reduced rate of rotting fol-

TABLE 3. Mean numbers of alfalfa plants killed by Sclerotium rolfsii in two experiments with plants of six ages from three populations, and significant differences between populations ${ }^{\mathrm{x}}$

\begin{tabular}{lcc}
\hline Experiment & Alfalfa population $^{\mathrm{y}}$ & Population mean $^{\mathrm{z}}$ \\
\hline 1 & Delta & $2.78 \mathrm{a}$ \\
& MSR & $2.20 \mathrm{~b}$ \\
2 & STR & $1.80 \mathrm{~b}$ \\
& Delta & $3.15 \mathrm{a}$ \\
& MSR & $2.40 \mathrm{~b}$ \\
& STR & $2.33 \mathrm{~b}$ \\
\hline
\end{tabular}

$\overline{\mathrm{x}}$ Mean numbers of plants killed in 10 replicate pots per age group with eight plants per pot.

${ }^{y}$ Delta is a commercial cultivar. MSR was selected from Delta for resistance to Sclerotinia trifoliorum by leaf inoculations. STR was selected from Delta for resistance to Sclerotinia trifoliorum by stem inoculations.

${ }^{\mathrm{z}}$ Means within experiments followed by the same letter do not differ significantly at $P=0.05$. lowing mycelial inoculations, is expressed in excised leaf tissues of each of seven alfalfa populations selected for resistance to Sclerotinia trifoliorum from five cultivars. Six of the seven populations were selected largely or entirely on the basis of leaf-tissue responses to Sclerotinia trifoliorum. The consistency of relatively resistant responses to Sclerotium rolfsii in these populations indicates that factors for quantitative host resistance to Sclerotinia trifoliorum and Sclerotium rolfsii are related in alfalfa leaf tissue. Although numerous plant species are common hosts for both Sclerotinia spp. and Sclerotium rolfsii, to our awareness this is the first demonstration (22) of a commonality of quantitative resistance to the two pathogens in the same host plant.

Results further demonstrate that, in two populations previously selected from cv. Delta for quantitative resistance to Sclerotinia trifoliorum (STR and MSR) (18,21), similar resistance to Sclerotium rolfsii also is expressed as reduced mortality following whole-plant inoculations. Results were consistent in that each selected population manifested less mortality than Delta when averaged across plant ages in both experiments. Therefore, selection for quantitative resistance to Sclerotinia trifoliorum in alfalfa gives enhanced resistance to Sclerotium rolfsii as manifested both by excised-leaf and whole-plant inoculations.

The relatedness of resistance to Sclerotinia trifoliorum and Sclerotium rolfsii in leaf tissue and whole plants of the common host plant, alfalfa, supports the concept that these pathogens have similar mechanisms of parasitism. Although most studies have been conducted independently for the two genera, similar conclusions and hypotheses have been advanced. Oxalic acid and pectinolytic enzymes are considered the principal compounds involved in parasitism by both Sclerotinia spp. $(3,6,7,12,13,16,26)$ and Sclerotium rolfsii $(3,6,23)$; these may act independently (7) or synchronously $(3,12,23)$ to break down cell walls and suppress host defensive responses $(6,12)$. If these or other mechanisms of parasitism are similar for Sclerotinia spp. and Sclerotium rolfsii, as past studies suggest, then host resistance to either pathogen also

TABLE 4. Mean numbers of surviving plants of four alfalfa cultivars, and of populations selected from them for resistance to Sclerotinia trifoliorum and selected at random, following whole-plant inoculations with Sclerotinia trifoliorum $^{\mathrm{w}}$

\begin{tabular}{llc}
\hline & \multicolumn{2}{c}{ Mean no. of surviving plants ${ }^{\mathrm{y}}$} \\
\cline { 2 - 3 } Source cultivar, population ${ }^{\mathrm{x}}$ & Experiment 1 & Experiment 2 \\
\hline Magnum-III-Wet & $2.17 \mathrm{a}$ & $0.83 \mathrm{a}$ \\
Parent cultivar & $1.25 \mathrm{a}$ & $0.08 \mathrm{a}$ \\
Random & $3.50 \mathrm{~b}$ & $2.25 \mathrm{~b}$ \\
Resistant & & \\
Pioneer 5472 & $2.57 \mathrm{a}$ & $0.58 \mathrm{a}$ \\
Parent cultivar & $1.85 \mathrm{a}$ & $0.58 \mathrm{a}$ \\
Random & $4.07 \mathrm{~b}$ & $0.83 \mathrm{~b}$ \\
Resistant & & \\
WAMPR & $1.92 \mathrm{a}^{\mathrm{z}}$ & $1.25 \mathrm{a}$ \\
Parent cultivar & $2.33 \mathrm{a}$ & $0.83 \mathrm{a}$ \\
Random & $2.92 \mathrm{a}^{\mathrm{z}}$ & $2.50 \mathrm{~b}$ \\
Resistant & & \\
WL-323 & $3.00 \mathrm{a}$ & $1.25 \mathrm{a}$ \\
Parent cultivar & $3.08 \mathrm{a}$ & $4.32 \mathrm{a}$ \\
Random & $4.33 \mathrm{~b}$ & $\mathrm{~b}$ \\
Resistant & &
\end{tabular}

${ }^{\mathrm{w}}$ Mean number of surviving plants in 12 to 15 replicate pots, eight plants per pot, 24 days after inoculation of foliage with Sclerotinia trifoliorum.

$x$ Random populations were produced by intercrossing 10 plants selected at random from each cultivar. Resistant populations were produced by intercrossing 10 plants selected for resistance to Sclerotinia trifoliorum by leafinoculation techniques from 1,000 plants of each cultivar.

y Means within source cultivars and experiments not followed by the same letter differ significantly at $P=0.05$ according to the least significant difference test.

${ }^{\mathrm{z}}$ When results of experiments 1 and 2 were combined, the resistant population differed significantly at $P=0.05$ from both the parent cultivar and random populations, which did not differ from each other. 
should be effective against the other. Results of this study indicate that such a dual effectiveness of quantitative host resistance is expressed in alfalfa.

An alternative hypothesis for the cause of common quantitative resistance to Sclerotinia trifoliorum and Sclerotium rolfsii in alfalfa is that quantitative traits may exist that confer generalized resistance to these unrelated pathogens for reasons unrelated to their modes of parasitism. Some evidence is known in other pathosystems for the occurrence of similar or closely linked quantitative trait loci that are effective against diverse pathogens (27).

The trifoliolate leaflet inoculation technique, previously developed and evaluated for use with Sclerotinia trifoliorum on alfalfa (17), was also highly effective in discriminating between levels of resistance to Sclerotium rolfsii among alfalfa populations. These results indicate that the same technique could be used to select for resistance to Sclerotium rolfsii in alfalfa, and very likely also in other crops on which Sclerotium rolfsii is an economically important pathogen. Whole-plant inoculations, in contrast, would likely be impractical and comparatively ineffective to use in selecting for resistance to Sclerotium rolfsii in alfalfa because of the strong modifying influence of plant age on survival and the lack of opportunity for repeated testing of putative resistant selections.

These results confirm previous reports from Japan $(10,11)$ that quantitative resistance to Sclerotium rolfsii is present in alfalfa. They also demonstrate for the first time that plant age at time of inoculation with Sclerotium rolfsii has a major influence on mortality of alfalfa. The decreased susceptibility to Sclerotium rolfsii with increased plant age appears to parallel a similar situation with Sclerotinia trifoliorum, in which disease severity is reduced with early fall plantings that result in older, larger, and more resistant plants by the time that mycelial disease development is initiated (24). If mechanisms of parasitism are similar for Sclerotium rolfsii and Sclerotinia trifoliorum, and if host resistance to

TABLE 5. Mean scores for disease severity induced by Sclerotium rolfsii in excised leaf tissues of four alfalfa cultivars and of populations selected from them for resistance to Sclerotinia trifoliorum, and selected at random ${ }^{\mathrm{x}}$

\begin{tabular}{lcc}
\hline & \multicolumn{2}{c}{ Mean scores of disease severity } \\
\cline { 2 - 3 } Source cultivar, population & Experiment 1 & Experiment 2 \\
\hline Magnum-III-Wet & & \\
Parent cultivar & $4.35 \mathrm{a}$ & $5.18 \mathrm{a}$ \\
Random & $4.38 \mathrm{a}$ & $5.42 \mathrm{a}$ \\
Resistant & $2.37 \mathrm{~b}$ & $4.48 \mathrm{~b}$ \\
Pioneer 5472 & & \\
Parent cultivar & $3.75 \mathrm{a}$ & $4.74 \mathrm{a}$ \\
Random & $4.38 \mathrm{a}$ & $4.68 \mathrm{a}$ \\
Resistant & $2.30 \mathrm{~b}$ & $3.75 \mathrm{~b}$ \\
WAMPR & & \\
Parent cultivar & $4.24 \mathrm{a}$ & $4.76 \mathrm{~b}$ \\
Random & $3.96 \mathrm{a}$ & $4.92 \mathrm{a}$ \\
Resistant & $2.94 \mathrm{~b}$ & $4.25 \mathrm{c}$ \\
WL-323 & & \\
Parent cultivar & $5.02 \mathrm{a}$ & $3.76 \mathrm{a}$ \\
Random & $5.05 \mathrm{a}$ & $3.84 \mathrm{a}$ \\
Resistant & $4.31 \mathrm{~b}$ & $3.11 \mathrm{~b}$ \\
\hline
\end{tabular}

${ }^{x}$ Each value is the mean disease score for 50 replicate leaf disks, one disk per plant. High mean scores indicate greater severity of symptoms, low mean scores indicate lesser severity. Scores of 1 to 7 were assigned inversely according to days on which leaf disks became completely necrotic within 1 week after inoculation. For leaf disks not completely necrotic after 1 week, scores of 0.00 to 0.99 were assigned according to estimates of percentages of tissue that were necrotic.

${ }^{y}$ Random populations were produced by intercrossing 10 plants selected at random from each cultivar. Resistant populations produced by intercrossing 10 plants selected for resistance to Sclerotinia trifoliorum by leaf-inoculation techniques from 1,000 plants of each cultivar.

${ }^{\mathrm{z}}$ Means within experiments and source cultivars not followed by the same letter differ significantly at $P=0.05$ according to the least significant difference test. these two pathogens is related as demonstrated here, then factors such as plant age that strongly influence host-pathogen interactions in one disease also may be expected to manifest parallel effects in the other.

\section{ACKNOWLEDGMENTS}

Mention of a trademark or proprietary product does not constitute an endorsement or warranty of the product by the U.S. Department of Agriculture and does not imply its approval to the exclusion of other products that may also be suitable.

\section{LITERATURE CITED}

1. Allison, J. L. 1952. Sclerotium rolfsii, a destructive pathogen of alfalfa and ladino clover. (Abstr.) Phytopathology 42:1.

2. Aycock, R. 1966. Stem rot and other diseases caused by Sclerotium rolfsii. N. C. Agric. Exp. Stn. Tech. Bull. 174.

3. Bateman, D. F., and Beer, S. V. 1965. Simultaneous production and synergistic action of oxalic acid and polygalacturonase during pathogenesis by Sclerotium rolfsii. Phytopathology 55:204-211.

4. Birch, R. G. 2001. Quantitative resistance. Page 843 in: Encyclopedia of Plant Pathology. O. C. Maloy and T. D. Murray, eds. John Wiley \& Sons, New York.

5. Farr, D. F., Bills, G. F., Chamuris, G. P., and Rossman, A. Y. 1989. Fungi on Plants and Plant Products in the United States. The American Phytopathological Society, St. Paul, MN.

6. Ferrar, P. H., and Walker, J. R. L. 1993. o-Diphenol oxidase inhibitionan additional role for oxalic acid in the phytopathogenic arsenal of Sclerotinia sclerotiorum and Sclerotium rolfsii. Physiol. Mol. Plant Pathol. 43:415-422.

7. Godoy, G., Steadman, J. R., Dickman, M. B., and Dam, R. 1990. Use of mutants to demonstrate the role of oxalic acid in pathogenicity of Sclerotinia sclerotiorum on Phaseolus vulgaris. Physiol. Mol. Plant Pathol. 37:179-191.

8. Grant, V. 1975. Genetics of Flowering Plants. Columbia University Press, New York.

9. Halimi, E. S., and Rowe, D. E. 1998. Stem-tip inoculation of alfalfa with Sclerotinia trifoliorum: II. Performance of $\mathrm{S}_{1}$ and $\mathrm{F}_{1}$ progenies from resistant and susceptible selections. Crop Sci. 38:23-26.

10. Inami, S., Kanbe, M., and Fujimoto, F. 1986. Breeding varieties of lucerne with resistance to southern blight. III. Increase in resistance according to advance of selection generation and heritability values. J. Jpn. Soc. Grassland Sci. 32:218-224.

11. Inami, S., and Suzuki, S. 1981. Breeding alfalfa, Medicago sativa L., for southern blight resistance. I. Varietal differences of the disease injury. J. Jpn. Soc. Grassland Sci. 26:360-364.

12. Marciano, P., Di Lenna, P., and Magro, P. 1983. Oxalic acid, cell walldegrading enzymes and $\mathrm{pH}$ in pathogenesis and their significance in the virulence of two Sclerotinia sclerotiorum isolates on sunflower. Physiol. Plant Pathol. 22:339-345.

13. Maxwell, D. P., and Lumsden, R. D. 1970. Oxalic acid production by Sclerotinia sclerotiorum in infected bean and in culture. Phytopathology 60:1395-1398.

14. Pennypacker, B. W. 2000. Differential impact of carbon assimilation on the expression of quantitative and qualitative resistance in alfalfa (Medicago sativa). Physiol. Mol. Plant Pathol. 57:87-93.

15. Pierson, P. E., and Rhodes, L. H. 1992. Effect of culture medium on the production of oxalic acid by Sclerotinia trifoliorum. Mycologia 84:467469.

16. Pierson, P. E., St. Martin, S. K., and Rhodes, L. H. 1994. Selection for resistance to Sclerotinia crown and stem rot in the field and greenhouse. Page 29 in: Rep. North Am. Alfalfa Improv. Conf. 34th. U.S. Dep. Agric. Beltsville, MD.

17. Pratt, R. G. 1996. Screening for resistance to Sclerotinia trifoliorum in alfalfa by inoculation of excised leaf tissue. Phytopathology 86:923-928.

18. Pratt, R. G., and Rowe, D. E. 1994. Responses to selection for resistance to Sclerotinia trifoliorum in alfalfa by stem inoculations. Plant Dis. 78:826-829.

19. Pratt, R. G., and Rowe, D. E. 1995. Comparative pathogenicity of isolates of Sclerotinia trifoliorum and S. sclerotiorum on alfalfa cultivars. Plant Dis. 79:474-477.

20. Pratt, R. G., and Rowe, D. E. 1995. Reduction in yield as an indicator of relative resistance to Sclerotinia trifoliorum in alfalfa. (Abstr.) Phytopathology 85:1169.

21. Pratt, R. G., and Rowe, D. E. 1996. Registration of Mississippi Sclerotinia-Resistant (MSR) alfalfa germplasm. Crop Sci. 36:821-822.

22. Pratt, R. G., and Rowe, D. E. 1998. Resistance to Sclerotium rolfsii in 
populations of alfalfa selected for resistance to Sclerotinia trifoliorum. Page 32 in: Rep. North Am. Alfalfa Improv. Conf. 36th. U. S. Dep. Agric. Beltsville, MD.

23. Punja, Z. K., Huang, J.-S., and Jenkins, S. F. 1985. Relationship of mycelial growth and production of oxalic acid and cell wall degrading enzymes to virulence in Sclerotium rolfsii. Can. J. Plant Pathol. 7:109117.

24. Rhodes, L. H., and Gilbert, R. G. 1990. Sclerotinia crown and stem rot. Pages 26-28 in: Compendium of Alfalfa Diseases. 2nd ed. D. L.
Stuteville and D. C. Erwin, eds. The American Phytopathological Society, St. Paul, MN.

25. Robinson, R. A. 1981. Ecological aspects of disease resistance. Pages 235-258 in: Plant Disease Control: Resistance and Susceptibility. R. C. Staples and G. H. Toenniessen, eds. John Wiley \& Sons, New York.

26. Scott, S. W., and Fielding, A. H. 1982. Polysaccharide degrading enzymes of Sclerotinia trifoliorum. Trans. Br. Mycol. Soc. 78:166-170.

27. Young, N. D. 1996. QTL mapping and quantitative disease resistance in plants. Annu. Rev. Phytopathol. 34:479-501. 